\title{
The use of 'real-time' complement analysis to differentiate atypical haemolytic uraemic syndrome from other forms of thrombotic microangiopathies
}

We read with great interest the recent correspondence of Dr Cataland and colleagues (Cataland et al, 2012), who appropriately pointed out that symptoms alone cannot differentiate thrombotic thrombocytopenic purpura (TTP) from atypical haemolytic uraemic syndrome (aHUS) in patients with thrombotic microangiopathies (TMAs). The data presented (Cataland et al, 2012) indicated that alternative diagnoses to TTP, including aHUS, should be considered in TMA patients with non-deficient ADAMTS13 activity $(>10 \%)$, moderate thrombocytopenia $\left(>30 \times 10^{9} / 1\right)$, pronounced abnormalities of renal function, and suboptimal response to plasma exchange (PEX) (absence of a steadily declining lactate dehydrogenase level and an increase in the platelet count after 4$5 \mathrm{~d}$ of daily PEX). Cataland et al (2012) concluded that, in the absence of an objective test to reliably diagnose aHUS, the combination of the above laboratory and clinical response data should help clinicians to identify patients who may benefit from therapy with the complement-inhibiting drug, eculizumab.

The clinical data-based objective criteria, as described by Cataland et al (2012), seems to be valid and highly practical, however, based on our latest diagnostic experiences, we would like to suggest the use of additional, parallel 'realtime' complement testing in this setting. Given that ongoing pathological activation and consumption of the alternative complement pathway is the core factor in the pathophysiology of aHUS (Noris \& Remuzzi, 2009), we hypothesized that functional testing of the alternative pathway and measurement of the alternative pathway components $\mathrm{C} 3$ and factor
B, may provide valuable diagnostic information in patients with acute aHUS, and differentiate them from patients with other forms of TMA.

Samples from 55 patients with an acute TMA episode [defined as microangiopathic haemolytic anaemia and thrombocytopenia $\left.\left(<130 \times 10^{9} / \mathrm{l}\right)\right]$ were consecutively referred to our research laboratory between April 2008 and February 2012, and parallel testing of ADAMTS13 activity and complement parameters were performed for all patients according to current guidelines (Ariceta et al, 2009; Taylor et al, 2010; Loirat \& Fremeaux-Bacchi, 2011; Roumenina et al, 2011). Functional assessment of the alternative pathway was done with the Wieslab ${ }^{\circledR}$ (Euro Diagnostica, Malmö, Sweden) alternative pathway enzyme linked immunosorbent assay kit (Seelen et al, 2005), C3 was measured by immunoturbidimetry and factor $\mathrm{B}$ by radial immune diffusion. Demographic and laboratory data are presented in aggregate for patients with final diagnosis of aHUS, TTP and typical $(\mathrm{D}+)$ HUS in Table I. The following criteria were used to establish the final diagnosis (Besbas et al, 2006; Scheiring et al, 2010): aHUS: acute renal failure, lack of bloody diarrhoea, non-deficient ADAMTS13 activity (>7\%) and presence of complement genetic abnormalities (four cases with complement-factor $\mathrm{H}$-related protein 1 deficiency with anti-factor $\mathrm{H}$ autoantibodies, two cases with complement factor $\mathrm{H}$ mutations, one case with membrane cofactor protein mutation, two recent cases with ongoing sequencing); TTP: presence of ADAMTS13 deficiency with ADAMTS13 inhibitors, no concomitant disease; D+HUS: sudden onset with typical

Table I. Pretreatment demographic and laboratory data for 55 TMA patients at the time of initial presentation.

\begin{tabular}{|c|c|c|c|c|c|c|c|}
\hline & \multirow[b]{2}{*}{$\begin{array}{l}\text { Age, years; } \\
\text { mean (range) }\end{array}$} & \multirow[b]{2}{*}{$\begin{array}{l}\text { Gender, } \\
\text { female; } \\
n(\%)\end{array}$} & \multirow{2}{*}{$\begin{array}{l}\text { ADAMTS13 } \\
\text { activity,\%; median } \\
\text { (interquartile } \\
\text { range) }\end{array}$} & \multicolumn{4}{|l|}{ Number (\%) } \\
\hline & & & & $\begin{array}{l}\text { Decreased } \\
\text { alternative pathway } \\
\text { activity results }\end{array}$ & $\begin{array}{l}\text { Decreased } \\
\text { C3 results }\end{array}$ & $\begin{array}{l}\text { Decreased } \\
\text { factor B } \\
\text { results }\end{array}$ & $\begin{array}{l}\text { All complement } \\
\text { parameters } \\
\text { decreased }\end{array}$ \\
\hline aHUS, $n=9$ & $7(0-20)$ & $4(44)$ & $44(27-80)$ & $9(100)$ & $9(100)$ & $7(78)$ & $7(78)$ \\
\hline TTP, $n=34$ & $41(13-71)$ & $30(88)$ & $0(0-3)$ & $2(6)$ & $4(12)$ & $5(15)$ & $1(3)$ \\
\hline $\mathrm{D}+\mathrm{HUS}, n=12$ & $18(1-68)$ & $8(67)$ & $66(56-76)$ & $1(8)$ & $3(25)$ & $1(8)$ & $0(0)$ \\
\hline$P$-value & $<0 \cdot 0001$ & $0 \cdot 015$ & $<0 \cdot 0001$ & $<0.0001$ & $<0 \cdot 0001$ & 0.0005 & $<0 \cdot 0001$ \\
\hline
\end{tabular}

aHUS, atypical haemolytic uremic syndrome; TTP, thrombotic thrombocytopenic purpura; D+HUS, diarrhoea-associated HUS; reference ranges: complement C3 0.9-1.8 g/l, alternative pathway activity 70-105\%, complement factor B antigen 70-130\%, ADAMTS13 67-151\%. 
signs of gastroenteritis with diarrhoea, lack of ADAMTS13 deficiency, good clinical response to supportive therapy and no long-term renal complication or disease recurrence (median follow up 11 months).

We observed low $(<70 \%)$ total alternative pathway activity and decreased C3 levels $(<0.9 \mathrm{~g} / \mathrm{l})$ in $100 \%$ of acute aHUS cases, whereas low $(<70 \%)$ factor B concentrations were present in seven out of the nine aHUS cases $(78 \%)$. All of the three complement results were decreased in $78 \%$ of aHUS cases (Table I). However, decreased complement parameters were very infrequent in TTP and D+HUS; only one TTP patient had three decreased complement results. The positive predictive value of having all the three complement parameters decreased (aHUS versus TTP plus D+HUS) was $0 \cdot 875$, whereas not having all of them decreased carried a negative predictive value of 0.957 . Based on these results, we considered testing of the complement alternative pathway useful for differentiating aHUS cases from other forms of TMA unrelated to secondary causes (including sepsis and disseminated intravascular coagulation, systemic autoimmune diseases, malignancies, transplantation).

The major limitation of the utilization of complement tests in this urgent clinical setting is their restricted availability. There are only a few laboratories worldwide providing complement alternative pathway testing for diagnostic purposes (see Ariceta et al, 2009), thus, it is an important immediate task to increase availability of these tests in local immunological/haematological laboratories. However, in the case of our 55 acute TMA patients, the average turnaround time (including transportation from other cities or countries) until functional testing of the alternative pathway, measuring C3, factor B and ADAMTS13 activity, was 3-5 working days. Our laboratory treats these tests as urgent for patients with acute TMA, if notified prior to sample shipping (ADAMTS13 and alternative pathway activity testing with C3 is performed within 1 working day).

The time interval of 3-5 d for complement testing fits closely to the proposal of Cataland et al (2012): the initial investigations for concomitant diseases and judgment of response to PEX in TMA patients may also take 4-5 d. Thus, if complement and ADAMTS13 investigations are initiated at the earliest available time-point (preferably before the initiation of PEX, although prior plasma therapy does not make testing impossible), the decision whether PEX should be stopped or continued, with or without alternative treatment (B-cell inhibition with rituximab or complement inhibition with eculizumab) can be made based on the results of sufficiently specific laboratory tests with good positive- and negative-predictive values.

\section{Acknowledgement}

Research funding: Hungarian National Research Fund (OTKA 100687).

\section{Author contributions}

$\mathrm{ZP}, \mathrm{LV}$ and GF designed the study, performed the research, analysed the data and wrote the manuscript. We thank all the clinicians who referred their patients for complement and ADAMTS13 investigations and provided clinical data.

\section{Zoltán Prohászka \\ Lilian Varga \\ George Füst \\ IIIrd Department of Medicine, Research Laboratory, Faculty of Medi- cine, Semmelweis University, Budapest, Hungary \\ E-mail: prohoz@kut.sote.hu}

Keywords: thrombotic thrombocytopenic purpura, atypical haemolytic uraemic syndrome, complement alternative pathway, ADAMTS13, differential diagnosis

First published online 22 May 2012 doi: $10.1111 / j .1365-2141.2012 .09168 . x$

\section{References}

Ariceta, G., Besbas, N., Johnson, S., Karpman, D., Landau, D., Licht, C., Loirat, C., Pecoraro, C., Taylor, C.M., Van de Kar, N., Vandewalle, J. \& Zimmerhackl, L.B. (2009) Guideline for the investigation and initial therapy of diarrhea-negative hemolytic uremic syndrome. Pediatric Nephrology, 24, 687-696.

Besbas, N., Karpman, D., Landau, D., Loirat, C., Proesmans, W., Remuzzi, G., Rizzoni, G., Taylor, C.M., Van de Kar, N. \& Zimmerhackl, L.B. (2006) A classification of hemolytic uremic syndrome and thrombotic thrombocytopenic purpura and related disorders. Kidney International, 70, 423-431.

Cataland, S.R., Yang, S. \& Wu, H.M. (2012) The use of ADAMTS13 activity, platelet count, and serum creatinine to differentiate acquired thrombotic thrombocytopenic purpura from other thrombotic microangiopathies. British Journal of Haematology, 157, 501-503.

Loirat, C. \& Fremeaux-Bacchi, V. (2011) Atypical hemolytic uremic syndrome. Orphanet Journal of Rare Diseases, 6, 60.

Noris, M. \& Remuzzi, G. (2009) Atypical hemolytic-uremic syndrome. New England Journal of Medicine, 361, 1676-1687.

Roumenina, L.T., Loirat, C., Dragon-Durey, M.A., Halbwachs-Mecarelli, L., Sautes-Fridman, C. \& Fremeaux-Bacchi, V. (2011) Alternative complement pathway assessment in patients with atypical HUS. Journal of Immunological Methods, 365, $8-26$.

Scheiring, J., Rosales, A. \& Zimmerhackl, L.B. (2010) Clinical practice. Today's understanding of the haemolytic uraemic syndrome. European Journal of Pediatrics, 169, 7-13.

Seelen, M.A., Roos, A., Wieslander, J., Mollnes, T. E., Sjoholm, A.G., Wurzner, R., Loos, M., Tedesco, F., Sim, R.B., Garred, P., Alexopoulos, E., Turner., M.W. \& Daha, M.R. (2005) Functional analysis of the classical, alternative, and MBL pathways of the complement system: standardization and validation of a simple ELISA. Journal of Immunological Methods, 296, 187-198.

Taylor, C.M., Machin, S., Wigmore, S.J. \& Goodship, T.H. (2010) Clinical practice guidelines for the management of atypical haemolytic uraemic syndrome in the United Kingdom. British Journal of Haematology, 148, 37-47. 